\title{
DENDÊ E SEU POTENCIAL DE USO: UMA PROSPECÇÃO TECNOLÓGICA
}

\author{
Maria Cecília Castelo Branco de Santana*1, Bruna Aparecida Souza Machado ${ }^{1}$, Tamiris Vilas Boas \\ Figueiredo $^{1}$, Itaciara Larroza Nunes ${ }^{2}$, Janice Izabel Druzian ${ }^{1}$ \\ ${ }^{1}$ Faculdade de Farmácia, Departamento de Análises Bromatológicas, Universidade Federal da \\ Bahia - UFBA, Salvador, Bahia - Brasil. \\ ${ }^{2}$ Escola de Nutrição da UFBA, Av. Araújo Pinho - no 32 - Canela, Salvador, Bahia - Brasil
}

\begin{abstract}
RESUMO
O dendê (Elaeis guineensis) é uma olaeginosa de grande produtividade. Seu óleo tem uma cor que vai do amarelo ao vermelho devido à presença de carotenóides, pigmentos com propriedades antioxidantes. Este óleo tem amplo uso comercial, na indústria de alimentos, farmacêutica e química. O objetivo deste trabalho foi realizar um estudo de prospecção para avaliar o panorama mundial da utilização do dendê. Foram realizadas consultas nos bancos de dados de patentes (Espacenet e no Instituto Nacional de Propriedade Industrial), utilizando palavras-chave em inglês para a pesquisa avançada (Advanced Search). O Brasil é um dos principais mercados destacando-se pela quantidade de documentos. A indústria de alimentos e de biotecnologia (biocombustíveis) são das que mais utilizam este recuso natural. A maioria das instituições depositantes é de natureza privada corporativa. Houve aumento de depósitos a partir do ano 2000, em virtude da inserção de novas tecnologias no beneficiamento do dendê e seus derivados.
\end{abstract}

Palavras Chave: Elaeis guineensi, Dendê; Tendências tecnológicas; Prospecção.

\section{ABSTRACT}

Oil palm (Elaeis guineensis) is an oleaginous plant with high productivity. Its oil has a color ranging from yellow to red due to the presence of carotenoids which are pigments with antioxidant properties. This oil has wide commercial use in the food, pharmaceutical and chemical industries. The objective of this study was a prospective study to assess the global picture of the use of palm oil. Searches were performed in the free databases of patent applications (Espacenet and the Brazilian National Institute of Industrial Property), using keywords and Advanced Search option. Brazil is one of the main markets being distinguished by the high amount of documents. The food industry and biotechnology (biofuels) are the ones that use more this natural resource. Most depositants are private corporations. There was an increase of patent applications since 2000 due to the inclusion of new technologies in the processing of palm oil and its derivatives.

Key words: Elaeis guineensis; Palm oil; Technology trends; Prospecting.

Área tecnológica: Alimentos

Cadernos de Prospecção - ISSN 1983-1358 (print) 2317-0026 (online), 2013, vol.6, n.4, p.516-525.

D.O.I.: http://dx.doi.org/10.9771/S.CPROSP.2013.006.055 


\section{INTRODUÇÃO}

A palmeira Elaeis guineensis, conhecida no Brasil como "dendê" e também como "palma", é oriunda do Oeste da África, chegando ao país no século XVII com os escravos e rapidamente se adaptou no litoral do sul da Bahia. Seu cultivo em larga escala se iniciou na primeira metade do século XX nas ex-colônias francesas da África Ocidental, além da Malásia e Indonésia, maiores produtores mundiais da atualidade. As primeiras plantações comerciais no Brasil, na Bahia e no Pará, datam da década de 1960 (VIEGAS e MULLER, 2000).

O óleo extraído desta palmeira é oriundo da polpa do fruto do dendezeiro e se caracteriza por uma cor que vai do amarelo ao vermelho devido à presença de uma grande quantidade de carotenóides, que são pigmentos com propriedades antioxidantes. As variedades mais cultivadas no Brasil são a dura, a tenera e psífera, as quais são diferenciadas pela espessura da casca da semente. A variedade mais utilizada comercialmente é a tenera, produto do cruzamento das variedades dura x psífera. $\mathrm{O}$ óleo de dendê apresenta consistência semi-sólida a temperatura ambiente, devido ao alto teor de ácidos graxos saturados, que por fracionamento fornece duas frações: a oleína e a estearina (TRIGUEIRO e PENTEADO, 1993).

O dendê é a oleaginosa de maior produtividade no planeta, com rendimento de até 4 a 6 ton. de óleo por hectare/ano. Isto se deve, principalmente, a estudos conduzidos nos últimos 50 anos pelo CIRAD, instituição francesa de pesquisa de óleos e oleaginosas, o que resultou em um aumento de $300 \%$ na produtividade média desta espécie segundo dados da EMBRAPA (Empresa Brasileira de Pesquisa Agropecuária).

Esta palmácea pode crescer até uma altura de 20 metros quando atinge o fim de sua vida econômica, por volta dos 25 anos. Possui de 35 a 50 folhas, que atingem 5 a 7 metros de comprimento e pesam de 5 a $8 \mathrm{~kg}$. cada. Os cachos, que demoram de 5 a 6 meses para atingir a maturidade a partir da polinização, pesam, em geral, de 10 a $30 \mathrm{~kg}$, contém em média 1500 frutos e são produzidos a uma taxa variável, conforme a época do ano (CONCEIÇÃO e MULLER, 2000). Além disso, por se tratar de uma cultura permanente, há uma produção contínua ao longo do ano, sem problemas de sazonalidade (KALTNER e FURLAN Jr., 2000).

As exigências climáticas do dendezeiro limitam o estabelecimento da cultura aos trópicos, em geral a uma faixa de $+/-10$ graus de latitude em torno do Equador, onde 95\% dos plantios existentes no mundo estão localizados. Desta forma, são poucos os países onde a cultura pode ser estabelecida, apenas trechos da América do Sul, África e Sudeste da Ásia. No território brasileiro, apenas a região Amazônica e uma faixa estreita do litoral da Bahia atendem às exigências edafoclimáticas para o cultivo do dendê (FURLAN et al., 2006). Porém, mais de $88 \%$ da área plantada encontra-se no estado do Pará, assim como a maioria das empresas produtoras de óleo (AGRIANUAL, 2008).

O óleo de palma tem amplo uso comercial, a saber (MPOB, 2007):

- Uso alimentício: direta ou indiretamente, o óleo faz parte de margarinas, de gorduras (para pães, biscoitos, massas, tortas) pó para sorvete, manteiga vegetal, óleo de cozinha e salada; ainda é substituto para a manteiga de cacau e fornece vitamina $\mathrm{E}$ e beta-caroteno (pro-vitamina A). Tradicionalmente, $80 \%$ de toda a produção é usada para tal finalidade;

- Uso industrial: é matéria prima para obtenção da estearina, oleína, glicerina, ácido láurico, ácido oléico, ácidos graxos, ésteres, entre outros; 
- Uso medicinal: algumas substâncias componentes do óleo (tocotrienóis e tocoferóis), tem propriedades anti-oxidantes, podendo representar papel protetor para células humanas, prevenir doenças cardíacas e câncer;

- Uso oleoquímico: o óleo de palma entra na composição de sabões, sabão em pó, sabonete, condicionador para cabelos, shampoos, velas, tintas, detergentes, laminação de aço (siderurgia), emulsificantes, entre outros.

Uma área bastante promissora para aplicabilidade do óleo de dendê é a produção do biodiesel. O Brasil tem capacidade para produzir combustíveis alternativos a partir de diversas espécies oleaginosas. No entanto, dado às características edafoclimáticas do sudeste da Bahia, o dendezeiro mostra-se como a cultura mais promissora para produção de óleo e sua conversão em biocombustível, via reação de transesterificação. Neste tipo de reação química, o óleo vegetal e o álcool, na presença de um catalisador ácido ou básico, resultam na obtenção de um éster metílico ou etílico, mais fino e com menor viscosidade, ou seja, o biocombustível e glicerina. Esta última, constitui-se em um subproduto com usos múltiplos na fabricação de tintas, adesivos, produtos farmacêuticos e na indústria têxtil, agregando valor ao produto primário - óleo vegetal, inegável ganho econômico (SOUZA, 2011).

Os ensaios realizados com óleo de dendê, segundo as normas da Agência Nacional de Petróleo (ANP), mostram que o combustível de óleo vegetal (biomassa), tem um poder de poluição muito abaixo daqueles apresentados pelo diesel de petróleo, além de ter um índice de cetano bem acima do mínimo exigido por ela. Comparado ao óleo diesel derivado de petróleo, o biodiesel pode reduzir em $78 \%$ as emissões líquidas de gás carbônico, considerando a reabsorção pelas plantas. Além disso, reduz em $90 \%$ as emissões de fumaça e praticamente elimina as emissões de dióxido de enxofre (EMBRAPA, 2011).

Diante de todo potencial econômico desta oleaginosa, o presente trabalho tem como objetivo realizar um estudo de prospecção para avaliar o panorama mundial da utilização do dendê e seus derivados, as principais áreas de aplicação destas tecnologias e seus países detentores.

\section{METODOLOGIA OU ESCOPO}

Para obtenção de dados atualizados referentes aos documentos de patentes e propriedade intelectual relacionados ao dendê, foram realizadas consultas nos bancos de dados de patentes. A busca foi realizada utilizando palavras-chave sobre a matriz dendê e processo de produção do óleo deste e seu emprego em diversos setores industriais. Foram empregados os termos em inglês para a pesquisa avançada (Advanced Search) no escritório europeu Espacenet (EP). Ressalta-se que foram utilizadas as seguintes palavras-chaves e suas combinações: "dendê", "dende oil", "palm oil" $\boldsymbol{e}$ “Elaeis guineensis".

Foi escolhida a pesquisa avançada (Advanced Search) da base de dados européia, pois esta compreende a coleção completa de pedidos de patentes em mais de 80 países, incluindo, por exemplo, os pedidos de patentes nacionais, Instituto Nacional de Propriedade Industrial (INPI), norte americanos, United States Patent and Trademark Office (USPTO) e via Patent Cooperation Treaty (PCT). 
Os dados coletados nos documentos de patentes foram tratados e discutidos pela análise de informações relevantes extraídas nestes documentos, o que permitiu se traçar um perfil superficial dos depositantes, ressaltando os principais países detentores destas tecnologias, a evolução do número de depósitos nos últimos anos, as principais áreas de aplicação destas tecnologias, etc.

Vale ressaltar que o termo "documento de patente" abrange pedidos de patente publicados ou patentes concedidas.

\section{RESULTADOS E DISCUSSÃO}

Como resultados das buscas efetuadas nos escritórios europeu (Espacenet- EP) e brasileiro (INPIInstituto Nacional de Propriedade Industrial) foram encontrados no total 40 (quarenta) documentos de patentes cuja avaliação segue nos subitens abaixo.

Das 40 patentes encontradas, a maior parte (34), referem-se à metodologia de processos enquanto apenas 6 se aplicam a produtos (Figura 1).

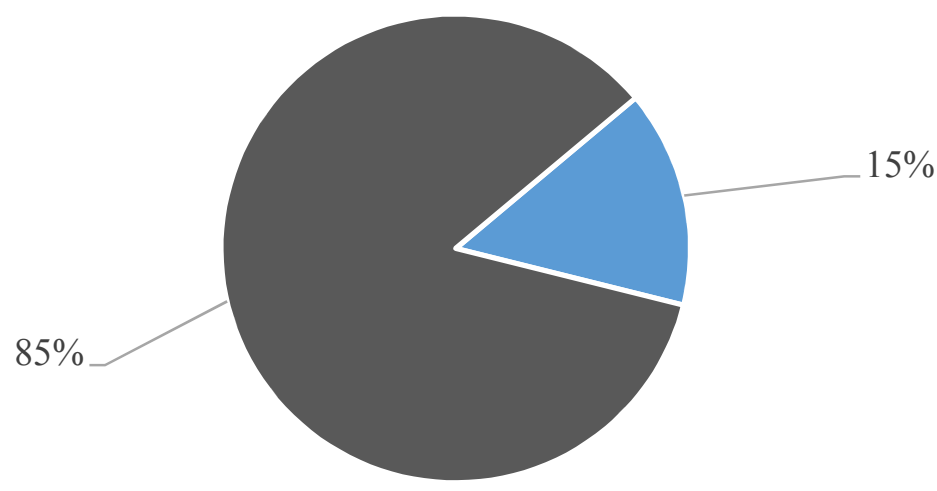

- Produto - Processo

Figura 1: Distribuição de patentes de acordo com critério processo $\mathrm{x}$ produto. Fonte: Autoria própria, 2012.

Dentre as diversas áreas de aplicação que as patentes depositadas abrangem, a maior parte refere-se à aplicação nos setores relacionados a alimentos e a bioquímica (Figura 2). O interesse da indústria de alimentos pelo óleo de dendê tem aumentado significativamente, uma vez que esse óleo tem se mostrado mais estável frente aos fatores adversos do processamento. Sua composição química peculiar com elevado teores de ácidos graxos saturados (AGS) favorece sua termoestabilidade e o torna ideal para aplicação nos processos de fritura dos alimentos. Além disso, a presença de teores significativos de carotenóides que podem variar de 500 a $1600 \mathrm{mg} / \mathrm{kg}$, de acordo com a variedade do fruto (ROSSO e MERCADANTE, 2007), são importantes sob o ponto de vista nutricional e na redução formação dos compostos na termodegradação. No Pará e Bahia, o óleo de palma da 
variedade tenera, chega a apresentar de 900 a $1140 \mathrm{mg} / \mathrm{kg}$ e de 550 a $650 \mathrm{mg} / \mathrm{kg}$ de carotenóides, respectivamente (TRIGUEIRO e PENTEADO, 1993).

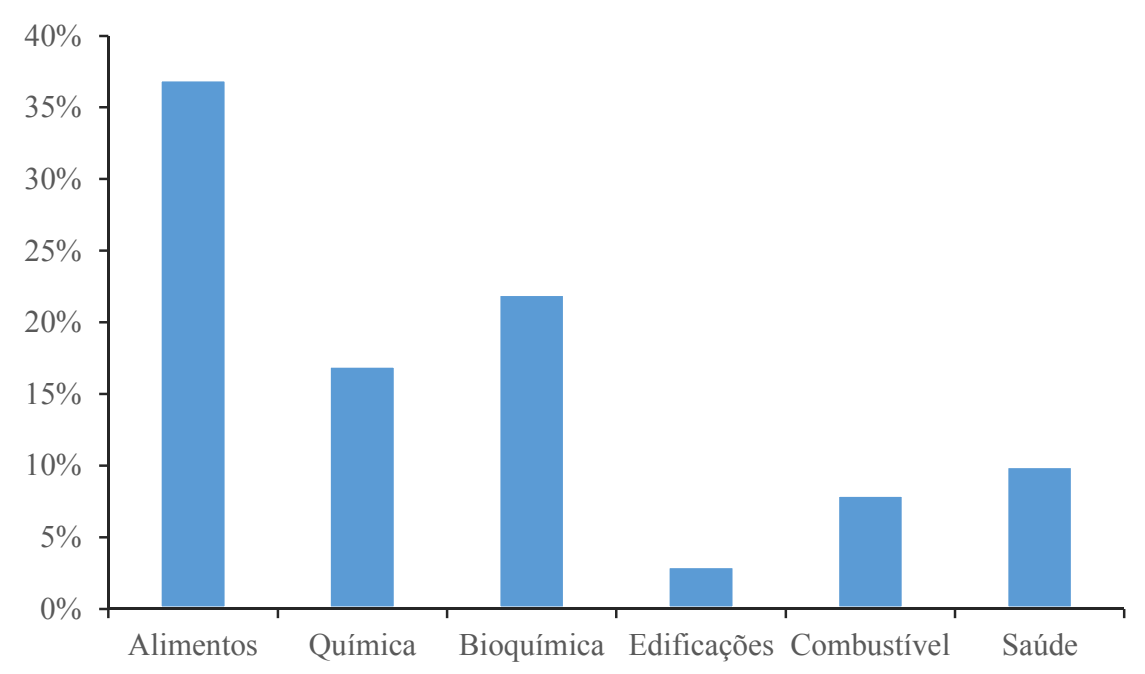

Figura 2: Distribuição de patentes de acordo com área de aplicação. Fonte: Autoria própria, 2012.

A utilização mais antiga relatada sobre utilização de óleo de dendê na indústria de alimentos é datada por volta de 1880 , quando este foi utilizado no processo de hidrogenação em substituição à gordura animal hidrogenada na fabricação de margarinas. Atualmente o óleo de dendê é utilizado em diversas formulações que utilizam a gordura vegetal hidrogenada ou outro tipo de gordura com características específicas para determinados tipos de produtos, como sorvetes, mistura para bolos, achocolatados, pastelaria fina, sopas instantâneas, etc. Quando submetido a processamento físico (sem utilização de produtos químicos), o azeite de dendê pode substituir os óleos usados tradicionalmente nas cozinhas, como os de soja, milho, canola, etc., sem transferir para o alimento os seus flavors característicos. Ainda através de um processamento mais elaborado, através de operações unitárias que reduzam a viscosidade, neutralize odor e sabor, retirem os pigmentos carotenóides, mantendo intacto o conteúdo de tocoferol (vitamina E), é possível se obter um novo produto, conhecido por RDB, bastante consumido na Europa, Estados Unidos e América Central, porém pouco conhecido no Brasil. (LODY, 2009)

Em relação à indústria bioquímica tem-se em destaque a utilização do óleo de dendê como matriz energética na fabricação do biodiesel. O Brasil apresenta um diferencial significativo, tendo diversidade de culturas que não competem com as de alimentação, terras agricultáveis, clima, solo, mão-de-obra, tecnologia e mercado interno crescente. No Brasil, existe grande diversidade de matérias-primas para a produção de biodiesel que incluem a mamona, o babaçu, a palma ou dendê, a soja, o algodão, o girassol, o amendoim e outras oleaginosas nativas que carecem ainda de muita pesquisa (LOURENÇO, 2009).

Dentre as oleaginosas cultivadas, o dendezeiro é a planta que apresenta a maior produtividade por área cultivada. Produz, em média, 10 vezes mais óleo do que a soja. Em condições ecológicas 
excelentes, pode produzir até 8 toneladas de óleo por ha/ano. O óleo de dendê está entre os óleos mais qualificados para o biodiesel, por sua composição, alta produtividade, seu baixo custo, produção distribuída ao longo de todo o ano, oferta regular e crescente, além de destinar-se a áreas de distintas de produção, não competindo com outros cultivos alimentares. O biodiesel precisará contar com todas as vantagens do óleo de dendê para realizar todo o seu potencial social, econômico e ecológico na matriz energética brasileira e mundial. (BARCELOS, 2008).

$\mathrm{Na}$ indústria química e farmacêutica mundial o dendê também participa de forma destacada na composição de vários produtos, seja de beleza como loções, cremes, shampoos, sabões como produtos de uso técnico, como graxas especiais para lubrificação, óleos lubrificantes, velas, emulsificantes, tintas e detergentes (LODY, 2009). A patente referente à Edificações é brasileira e apresenta um novo produto que tem como constituinte-base as fibras do dendê e que é utilizado na construção civil.

Analisando os documentos de patentes resultantes da busca efetuada notou-se que, em maioria (77\%), o depósito foi efetuado por uma instituição privada (Figura 3). Esses dados permitem inferir que a indústria tem investido em Pesquisa e Desenvolvimento (P\&D) e tem se preocupado em proteger essa tecnologia não só em seu território como em outros países, o que não anula as pesquisas realizadas pelas universidades e outros institutos de pesquisa.

No Brasil, a maioria das patentes foi depositada pelo Instituto Militar de Engenharia no Rio de Janeiro, todas na área de biotecnologia.

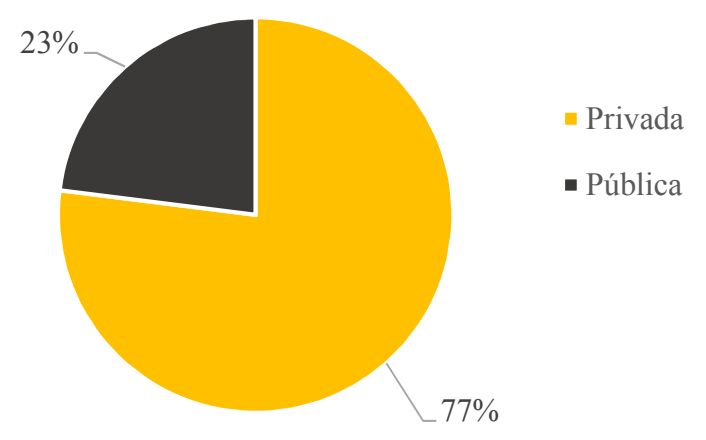

Figura 3: Natureza das intituições detentoras das patentes. Fonte: Autoria própria, 2012.

Apesar da minoria de patentes depositadas pertencerem à inventores independentes (Figura 4), foi identificada no Brasil uma grande quantidade de depositantes desta natureza, que estão iniciando a apropriação de suas descobertas, a maioria deles representados por escritórios de marcas e patentes, outro setor que têm se destacado em crescimento.

O fato de o dendê e sua cadeia produtiva serem objetos de muitas patentes depositadas por corporações denota a preocupação destas com o meio ambiente, no que se refere ao aproveitamento 
de resíduos oriundos de indústrias de diversos setores. Ainda percebe-se a necessidade do aproveitamento desse recurso natural, o que fortalece o agronegócio regional, agregando valor a cada ponto desta cadeia.

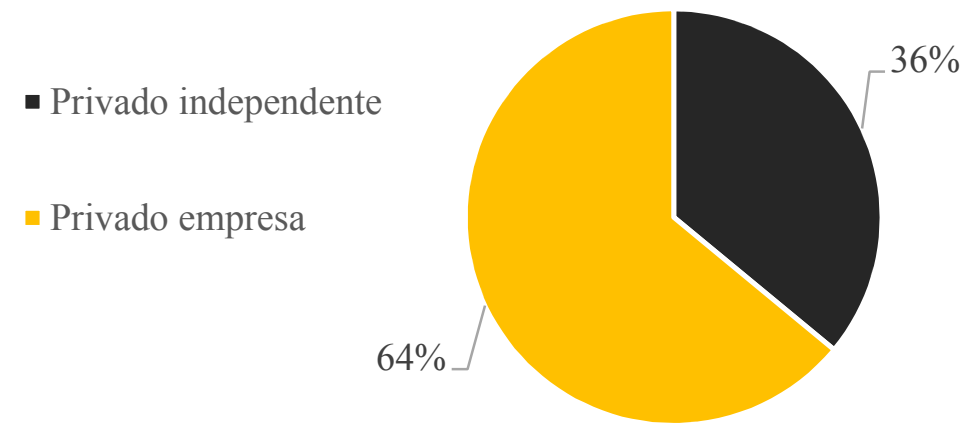

Figura 4: Perfil dos depositantes de natureza privada. Fonte: Autoria própria, 2012.

O Brasil apresentou a maioria da titularidade das patentes depositadas (Figura 5). Isso é atribuído ao fato de que o Brasil possui o maior potencial mundial para a produção do óleo de dendê dado aos quase 75 milhões de hectares de terras aptas à dendeicultura (SOUZA, 2011).

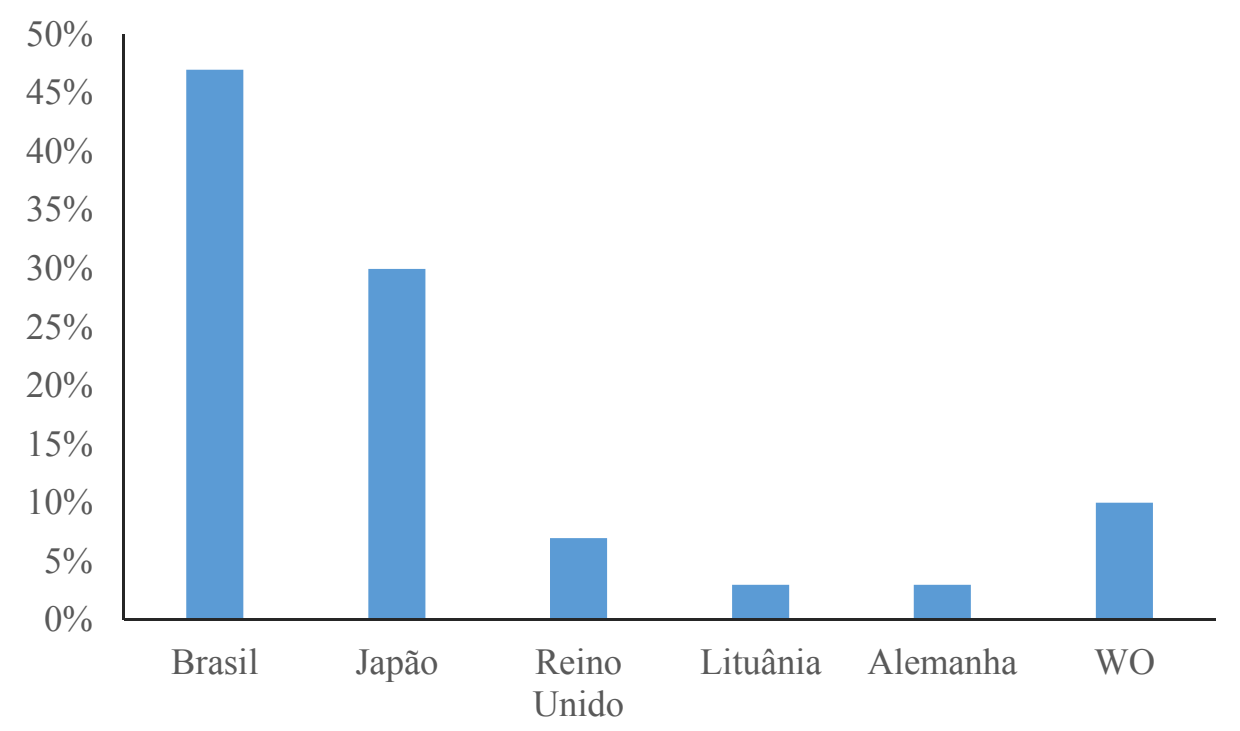

Figura 5: Distribuição das patentes de acordo com os países depositantes. Fonte: Autoria própria, 2012. 
As patentes japonesas levantadas na pesquisa apontam a engenharia genética e a biotecnologia como foco principal em seus documentos. $\mathrm{O}$ alto incentivo à pesquisa, a disponibilidade, o domínio de tecnologia e a grande necessidade de se compensar e resolver problemas de ineficiência de território para cultivo impulsionam pesquisas nas áreas de manipulação de genes para melhoramento das espécies, conservação de alimentos pelo uso de antioxidantes e desenvolvimento de energias alternativas.

As patentes brasileiras depositadas no INPI (Instituto Nacional de Propriedade Industrial) tiveram São Paulo e Rio de Janeiro como maiores detentores das titularidades (Figura 6). O incentivo à proteção intelectual difundido nas instituições presentes nestes estados é um fator considerável na avaliação destes dados.

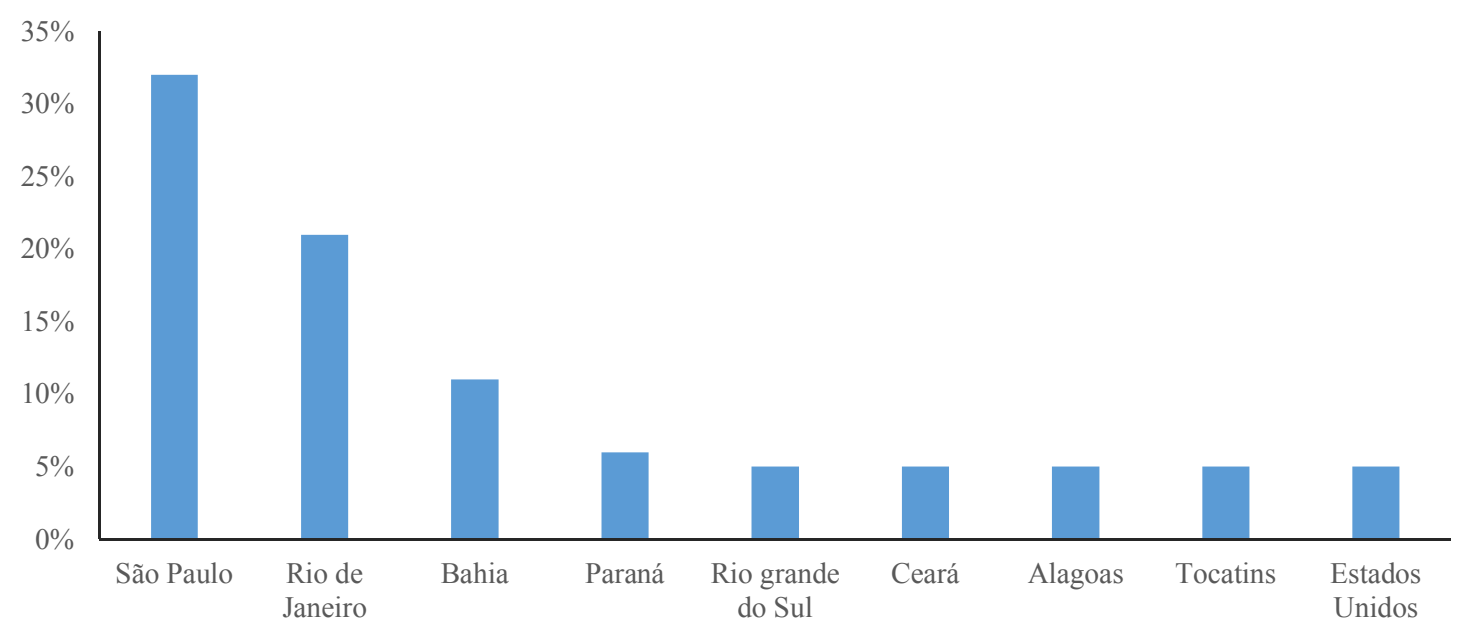

Figura 6: Distribuição das patentes de acordo com os estados depositantes. Fonte: Autoria própria, 2012

Apesar da utilização do dendê ser bastante antiga, o primeiro pedido de patente foi depositado em 1916; trata-se da patente que descreve o processo de hidrogenação do óleo de dendê como substituinte da gordura animal hidrogenada em margarinas. Essa patente, GB112164(A) tem titularidade pertencente ao Reino Unido e foi depositada por BRUYN LTD DE ; JOHN DE BRUYN.

Tem-se acompanhado a evolução dos pedidos de patentes com o passar dos anos, tendo um espantoso crescimento a partir do ano 2000 (ver Figura 6). Esse aumento foi impulsionado pelo avanço nas pesquisas relacionadas ao uso do dendê nas indústrias alimentícias e químicas e principalmente pelo excelente desempenho na cadeia do biodiesel. O volume total de biodiesel B100 produzido no Brasil em 2006 foi de $69.002 \mathrm{~m}^{3}$, saltando para $402.177 \mathrm{~m}^{3}$ em 2007, o que representa um salto bastante expressivo em relação à produção de 2005 , de apenas $736 \mathrm{~m}^{3}$ (ANP, 2008). 
Ações que propõem o beneficiamento das espécies oriundas da região norte e o extrativismo, o incentivo à pesquisa e à inovação também contribui para o crescimento de publicações e pedidos de patentes.

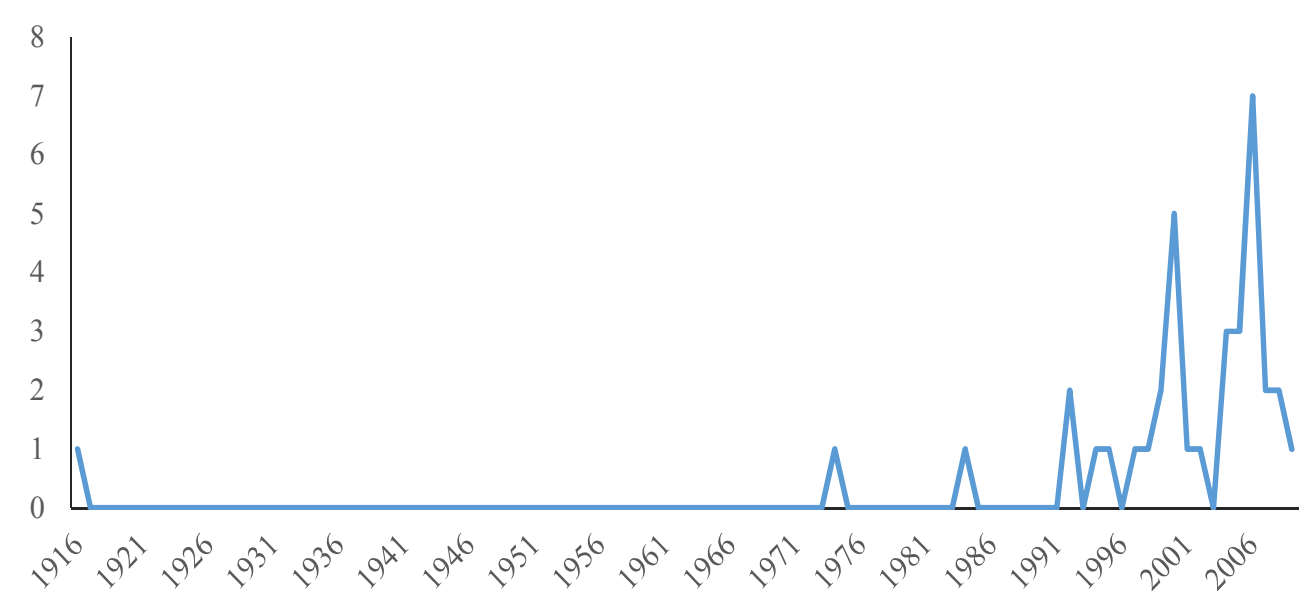

Figura 7: Evolução dos depósitos ao longo dos anos. Fonte: Autoria própria, 2012.

\section{COMENTÁRIOS FINAIS}

Através da análise dos documentos de patentes encontrados através da busca de tecnologias referentes ao dendê e seus derivados, como o óleo, entende-se que este é um agronegócio em expansão, cujo Brasil é um dos principais mercados, tanto produtor como consumidor. A indústria de alimentos e de biotecnologia, principalmente voltadas à produção de biocombustíveis, são das que mais utilizam este recuso natural, gerado maior volume de documentos de patentes. A maioria das instituições depositantes é de natureza privada corporativa. O Brasil destaca-se pela quantidade de documentos, sendo São Paulo e Rio de Janeiro os estados com maior número de depósitos, que tiveram aumento significativo a partir do ano 2000, em virtude da inserção de novas tecnologias no beneficiamento do dendê e seus derivados.

\section{REFERÊNCIAS}

AGRIANUAL. Anuário da Agricultura Brasileira, 2007, São Paulo, SP.

ANP-Agência Nacional de Petróleo, Gás Natural e Biocombustíveis. Produção de Biodiesel - B100 por produtor, 2008. Disponível em: $<$ http://www.anp.gov.br/doc/dados_estatisticos/Producao_de_ biodiesel_m3.xls>. Acesso em: 0000.00.

BARCELOS, E. Biodiesel de dendê, uma alternativa ecológica. (2011). Disponível em: $<$ http://www.biodieselbr.com/noticias/biodiesel/biodiesel-dende-alternativa-e-cologica-07-0708.htm>. Acesso em: 00 out. 2011. 
CONCEIÇÃO, E.; MULLER, A. "Botânica e Morfologia do Dendezeiro". In: Viegas, I, Muller, A. (eds), A Cultura do Dendezeiro na Amazônia Brasileira, 2000, 1 ed., cap. 2 Belém, Pará.

EMBRAPA, 2011. Disponível em: <http://www.embrapa.br/imprensa/noticias/2011/marco/1asemana/dende-importante-materia-prima-para-a-producao-dobiodiesel $/$ ? searchterm $=\mathrm{dend} \% \mathrm{C} 3 \% \mathrm{AA}>$. Acesso em: 00 00. 00 .

FURLAN Jr., J. et al. BIODIESEL: Porque tem que ser dendê. 2006, EMBRAPA, 1 ed. Belém, PA.

KALTNER, F. J.; FURLAN Jr., J. "Processamento Industrial de cachos de Dendê para Produção de Óleos de Palma e Palmiste". In: Viegas, I., Muller, A. (eds), A Cultura do Dendezeiro na Amazônia Brasileira, 2000, 1 ed., cap. 13. Belém, Pará.

LODY, R. Dendê: símbolo e sabor da Bahia. 2009. Editora SENAC, São Paulo-SP.

LOURENÇO, S.; Boletim Agência FAPESP. Disponível em: $<$ http://www.agencia.fapesp.br/materia/9839/especiais/biodiesel-feito-de-algas.htm>. Acesso em: 00 fev. 2009.

ROSSO, V. V.; MERCADANTE, A. Z. Identification and Quantification of Carotenoids, By HPLC-PDA-MS/MS, from Amazonian Fruits. J. Agric. Food Chem, n. 55, p. 5062-5072, 2007.

SOUZA, J. Dendê - Potencial para produção de energia renovável, 2011. Disponivel em: $<$ http://www.ceplac.gov.br/radar/Artigos/artigo9.htm>. Acesso em: 0000.00.

TRIGUEIRO, I. N. S.; PENTEADO, M. V. C. Características físicas, químicas e estado de oxidação de óleos de dendê brasileiros. Boletim do Centro de Pesquisa de Processamento de Alimentos, v. 11, n. 2, 1993.

VIEGAS, I., MULLER, A. A. Cultura do Dendezeiro na Amazônia Brasileira, 2000 , 1 ed., Embrapa Amazônia Oriental. Belém, Pará. 